water and agricultural chemicals are raising problems, and Vietnam showed the sensitivity of mangal to herbicides.

While many coastal-zone studies have been made over the past decades, most focused on the flora and fauna and their life cycles, and on descriptive ecology. The relatively few (and somewhat conflicting) studies of nutrient cycling, food webs and population dynamics must be greatly extended if forceful scientific arguments are to be advanced to reduce further destruction. High biological productivity is not enough. The benefit to man, direct or indirect, must be demonstrated if the developers are to be given pause. Subtle benefits such as denitrification, sulphuric acid reduction and assimilation of other pollution need to be further studied and emphasised. Much remains to be done, but this brilliant volume provides the basic source book for future research into this undervalued twilight zone between land and water.

G.V.T. MATTHEWS

\title{
Mammals of Borneo by Lord Medway. Kegan Paul, $£ 5$.
}

Lord Medway's sojourn in the Orient has been long by some standards, short by others, but most successful by any. Field keys and annotated check lists are often rather tedious, however useful, but Lord Medway has compiled a fascinating account of Bornean mammals. The tone of this second revised edition is set in the Introduction, which evokes the full flavour of the ecology of Bornean rain-forests and the history of studies there.

The twelve orders of mammals represented in Borneo by 34 families are described succinctly, with a key to species introducing the sections on the Insectivora, Chiroptera, Primates, Rodentia, Cetacea, Carnivora and the sub-section on Tragulidae (but not for the Cervidae). The examination of museum material has been thorough, but the descriptions of individual species are rather variable and those of some of the smaller mammals rather inadequate. Reference to distributions of those species occurring outside Borneo would have been useful; so too would have been some maps of distribution within Borneo.

In paperback, with 24 black-and-white plates and running to 172 pages, this is a most useful, concise and lively book, concluding with a comprehensive bibliography extending beyond the references cited to encompass other relevant faunistic, taxonomic and general works relating to Bornean mammals. Essential for any visitor to Borneo, it is also strongly recommended to anyone wishing to broaden their knowledge of Malesian wildlife, especially when read in conjunction with The Wild Mammals of Malaya by the same author. The Malaysian Branch of the Royal Asiatic Society are to be congratulated for sponsoring this venture, and in particular for this second edition.

DAVID J. CHIVERS

Tiger: The Story of the Indian Tiger, by Kailash Sankhala. Collins, $£ 7.95$.

In this highly readable and evocative account of the Indian tiger, illustrated with splendid colour photographs, the author distils the experience of twenty-five years, the later years more particularly devoted to the tiger. After serving in the Indian Forest Service, in 1962 he became Director of Delhi Zoological Park, and in 1972 head of Project Tiger, the world-wide attempt to save the Indian tiger from extinction. He records facts about the tiger which I have seen nowhere else mentioned: clearly, this was made possible only because he created for himself the unique experience of virtually 'living' with tigers both in captivity and in the wild for extended periods.

The first part of the book deals with the tiger in the wild and describes its hunting, feeding, family life, and relationship to prey and other animals in its habitat. It is interesting that the author does not consider that tigers hold territory, in variance with other observers, for example, McDougal in Nepal. There are, clearly, explanations for both propositions. The second part is concerned with his evaluation of man's impact on 
the tiger interpreted through his own special relationship with it. His years as Director of Delhi's Zoo are rich in anecdote, and surely marked the beginning of a new era in zoo management in India. As Director of Project Tiger, he introduced the 'pug mark tracer' as a main means of making a tiger count, and completed the first reliable tiger census based on extensive fieldwork. Kailash Sankhala has now returned to the Forest Service, after rendering signal service to arrest the decline of the Indian tiger, and so contributing to conservation of its habitat and other wildlife as well. He concludes with the belief-one to be fervently shared-that the tiger could now have an assured future. The only area in the book that jarred was his antipathic references to Jim Corbett. I am sure that Corbett neither intended to pontificate on tigers nor was he prone to exaggeration.

B. SESHADRI

\section{Pride of Lions, by Brian Bertram. Dent, $£, 6.50$.}

Of all the predatory mammals, lions, by virtue of their size and relatively open habitat, must be among the easiest to observe as individuals. But their very size, along with their sociable habits and longevity, make it exceedingly difficult to get a sufficiently detached view of an entire pride over a period of time sufficient to determine the pattern and significance of their social organization. Building on the work of his predecessors in East Africa-C.A.W. Guggisberg, with a lifetime of intermittent observation described in Simba: the life of a lion in 1961, George Schaller's pioneering work in the Serengeti, detailed in The Serengeti lion in 1972, and Judith Rudnai's study in Nairobi National Park published as The social life of the lion in 1973-Brian Bertram has considerably enhanced our understanding of the way a lion community operates. Making use of his intimate first-hand observation of lions in the Serengeti over four years, he has attempted to describe in general terms the various facets of the life of a pride-its composition and organisation, breeding cycle, territory and hunting -with only occasional reference to particular incidents or to the observations of others. The result is a very

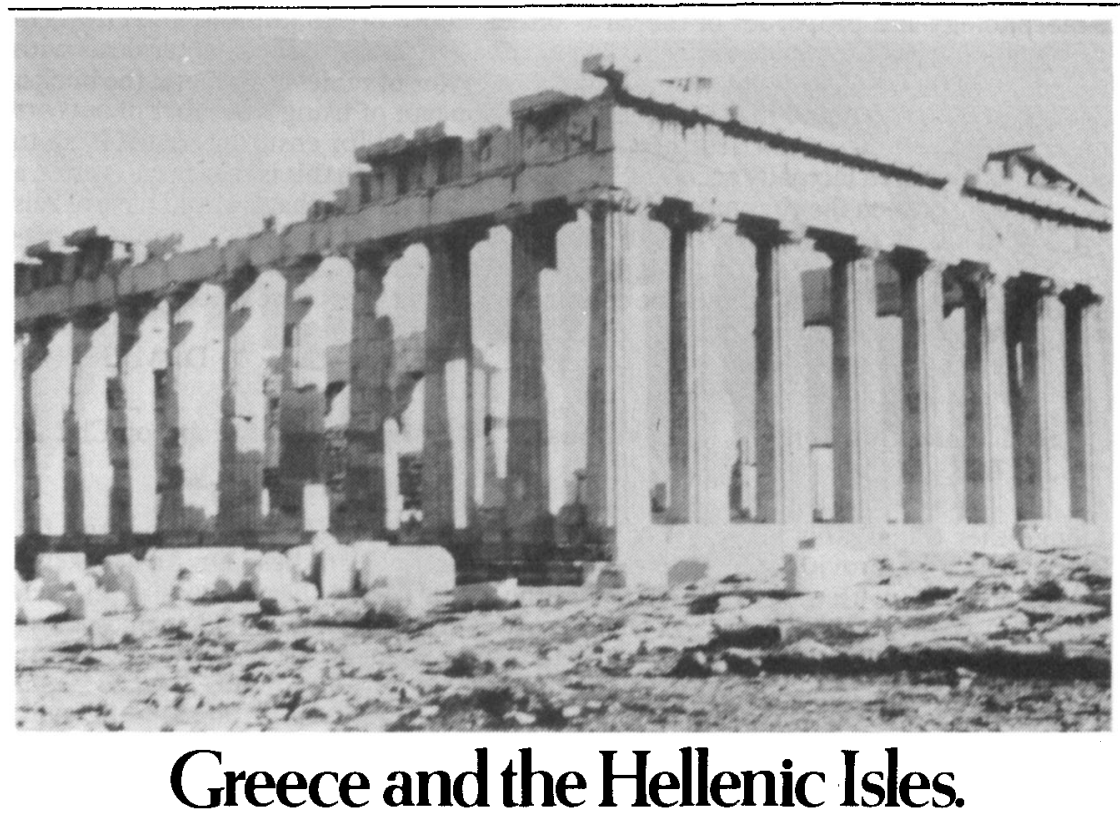

They'e closer than you think. 